Article

\title{
Discovery of Novel GMPS Inhibitors of Candidatus Liberibacter Asiaticus by Structure Based Design and Enzyme Kinetic
}

\author{
Jing Nan ${ }^{1}{ }^{\circledR}$, Shaoran Zhang ${ }^{2}$, Ping Zhan ${ }^{1}$ and Ling Jiang ${ }^{1, *}$ \\ 1 Ministry of Education Key Laboratory of Plant Biology, Huazhong Agricultural University, \\ Wuhan 430070, China; nanjing@webmail.hzau.edu.cn (J.N.); zhanping818@163.com (P.Z.) \\ 2 State Key Laboratory of Agricultural Microbiology, Huazhong Agricultural University, Wuhan 430070, China; \\ zsr@mail.hzau.edu.cn \\ * Correspondence: jiangling@mail.hzau.edu.cn
}

check for updates

Citation: Nan, J.; Zhang, S.; Zhan, P.; Jiang, L. Discovery of Novel GMPS Inhibitors of Candidatus Liberibacter Asiaticus by Structure Based Design and Enzyme Kinetic. Biology 2021, 10, 594. https://doi.org/10.3390/ biology10070594

Academic Editor: Dmitri Davydov

Received: 24 May 2021

Accepted: 25 June 2021

Published: 28 June 2021

Publisher's Note: MDPI stays neutral with regard to jurisdictional claims in published maps and institutional affiliations.

Copyright: (c) 2021 by the authors. Licensee MDPI, Basel, Switzerland. This article is an open access article distributed under the terms and conditions of the Creative Commons Attribution (CC BY) license (https:// creativecommons.org/licenses/by/ $4.0 /)$.
Simple Summary: The spread of citrus Huanglongbing caused significant damage to the world's citrus industry. Thermotherapy and chemical agents were used to control this disease; however, the effectiveness of these treatments is frequently inconsistent. In addition, CLas cannot be cultured in vitro. Therefore, structure-based virtual screening is a novel method to find compounds that work against CLas. This study used CLas GMPS as a target for high-throughput screening and selected some compounds which have a higher binding affinity to test their inhibition of CLas GMPS. Finally, two molecules were identified as the lead compound to control citrus HLB.

Abstract: Citrus production is facing an unprecedented problem because of huanglongbing (HLB) disease. Presently, no effective HLB-easing method is available when citrus becomes infected. Guanosine $5^{\prime}$-monophosphate synthetase (GMPS) is a key protein in the de novo synthesis of guanine nucleotides. GMPS is used as an attractive target for developing agents that are effective against the patogen infection. In this research, homology modeling, structure-based virtual screening, and molecular docking were used to discover the new inhibitors against CLas GMPS. Enzyme assay showed that folic acid and AZD1152 showed high inhibition at micromole concentrations, with AZD1152 being the most potent molecule. The inhibition constant $\left(\mathrm{K}_{\mathrm{i}}\right)$ value of folic acid and AZD1152 was $51.98 \mu \mathrm{M}$ and $4.05 \mu \mathrm{M}$, respectively. These results suggested that folic acid and AZD1152 could be considered as promising candidates for the development of CLas agents.

Keywords: Candidatus Liberibacter asiaticus; guanosine 5'-monophosphate synthetase; virtual screening; molecular docking; enzyme activity

\section{Introduction}

Huanglongbing (HLB) is the most damaging disease that is threatening citrus production worldwide [1-3]. HLB was caused by Candidatus L. africanus (Laf), Ca. L. americanus (Lam), and Ca. asiaticus (Las) [4,5]. Currently, HLB has been confirmed in 51 of the 140 citrus-producing countries [6]. Current control measures against CLas include insecticidal control, planting CLas-free trees, and removing infected trees [7,8]; however, these management strategies are inadequate depending on the stage of HLB epidemiology. Despite the positive effect of using broad-spectrum antibiotics to control CLas [9-11], these antimicrobials present two significant downsides: the emergence of bacterial resistance and impact on native bacterial populations [12,13]. Small moleculars specifically targeting CLas have also been identified [14-16]. In addition, plant defense inducers or activators may help decrease the influence of HLB [17-19]. Nevertheless, the effectiveness of these compounds is frequently inconsistent or controversial in field conditions [20]. These problems suggest that we should focus our research on the pathogen. Considering the current shortage of 
new drugs, one approach to solve this problem is to apply rational drug-design techniques towards conserved metabolic pathways.

Rapid proliferation is a typical feature of bacterial infections. The de novo purine biosynthesis pathway is ultimately responsible for the generation of inosine $5^{\prime}$-monophosphate, and provides the adequate purine nucleotides required for DNA replication and cell division [21]. The importance of the de novo purine biosynthesis in bacterial growth has been repeatedly described. GMP synthetase (GMPS), a class-I amidotransferase belonging to the glutamine amidotransferase family, is a vital protein in the de novo purine biosynthesis, which converts xanthosine $5^{\prime}$-monophosphate (XMP) to guanosine monophosphate (GMP) [22]. This catalytic reaction occurs in two physically distant domains: a GATase (glutamine amidotransferase) domain that provides the required ammonia from glutamine hydrolysis and an ATPPase (ATP pyrophosphatase) domain that catalyzes the formation of the XMP-adenyl complex [23]. In Staphylococcus aureus, deletion of guaA genes resulted in guanine auxotrophy, profound abnormalities in cell morphology, and avirulence in mouse infection models [24]. In Trypanosoma brucei, genetic knockout of GMPS led to depletion of guanine nucleotide pools; this parasite was only rescued by additional guanine or by the expression of GMPS [25]. These studies identify GMPS as an attractive target for future drug development.

GMPS is a promising target for antibacterial drug discovery; however, only a few GMPS inhibitors have been reported [26-28]. Although prokaryotic GMPSs have high sequence similarities, their sensitivities to the same inhibitor are different $[22,29,30]$. Hence, there is a need for novel compounds targeting specific GMPSs. In this study, the structure of CLas GMPS was predicted using homology modeling. Drug-like molecules from the ApexBio screening library were used for virtual screening. The molecules with the highest LibDock scores were used for docking and analysis through CDOCKER. Unfortunately, CLas could not be cultured thus far. Therefore, the effectiveness of these agents against CLas GMPS were verified in vitro. The molecules identified in our research may serve as parent compounds for further optimization to develop agents to control the HLB disease.

\section{Materials and Methods}

\subsection{Homology Modeling and Structure Validation}

A homology model of CLas GMPS (UniProt ID: C6XHZ4) was built by Swiss-Model (https:/ / swissmodel.expasy.org/interactive, accessed on 24 June 2021). The crystal structure of GMP synthase from Neisseria gonorrhoeae in the Protein Data Bank (PDB ID: 5TW7) was used to build the CLas GMPS homology model. The homology of CLas GMPS to Neisseria gonorrhoeae GMPS corresponds to $50.98 \%$ identity. This predicted model was further verified by Verify 3D [31] and Procheck [32].

\subsection{Virtual Screening}

Structure-based virtual screening was used to screen potential CLas GMPS inhibitors from approximately 5500 small molecule compounds available from the FDA-approved Drug Library, Natural Product Library Plus, and Inhibitor Library. The sdf file of these molecules was downloaded from ApexBio technology (https:/ / www.apexbio.cn/screeninglibrary.html, accessed on 24 June 2021). The LibDock section of Discovery Studio was utilized for virtual screening. LibDock is a rigid receptor-based docking suite for fast and accurate screening. LibDock employs protein site features as hotspots and then poses of rigid ligand are placed into the hotspots and matched as triplets [33]. The hotspots are used to choose the ligands to form stable complexes with the ligand-binding pocket of the receptor in LibDock module. Preparations for the use of LibDock included three steps. First, the receptor was prepared by adding hydrogen, minimizing the energy, and defining the binding site. Second, two shortcuts ("Prepare Ligands" and "Minimize Ligands") were used to prepare the ligands. Finally, the prepared protein and prepared ligands were selected for analysis. At the end of the docking procedure, all the docked poses were ranked according to the LibDock score. 


\subsection{Molecule Docking Study}

The CDOCKER module of Discovery Studio 2018 was used for molecular docking. CDOCKER is a molecular docking method which employs a CHARMm force field [34]. This force field was applied for both receptors and ligands to produce high-precision docking results. To prove the reliability of the result, two known GMPS inhibitors (DON and $\mathrm{ACI}$ ) and the compound from the LibDock result were selected as ligands. In the docking experiment, the structure of CLas GMPS was used as the receptor. The best pose of each molecular binding with the receptor was estimated according to the binding energy.

\subsection{Absorption, Distribution, Metabolism, and Excretion and Toxicity Prediction}

The ADME module of Discovery Studio 2018 was employed to calculate the absorption, distribution, metabolism, and excretion (ADME) of selected compounds. The set of estimated parameters included their aqueous solubility, blood-brain barrier penetration, hepatotoxicity, human intestinal absorption, and plasma protein binding level.

\subsection{Gene Cloning}

The guaA gene from Candidatus Liberibacter asiaticus (strain psy62) was amplified by PCR using the forward primer $5^{\prime}$-gcgcggatccatgcacaagagagaaagatcaag- $3^{\prime}$ and the reverse primer $5^{\prime}$-gcgcctcgagttattcccattcaatagttgc- $3^{\prime}$. After treatment with the restriction enzymes Bam $\mathrm{HI}$ and Xho I, the guaA gene fragment was ligated to the pET28atplus expression vector and transformed into E. coli DH5 $\alpha$. Colonies were picked up and subjected to DNA sequencing. The correct plasmid was then extracted for recombinant expression.

\subsection{Protein Expression and Purification of CLas GMPS}

The plasmid pET28atplus-CLas GMPS was transformed into E. coli BL21 (DE3) and the cells were cultured in LB media supplemented with $50 \mu \mathrm{g} / \mathrm{mL}$ of kanamycin at $37^{\circ} \mathrm{C}$. The culture was induced by adding $0.3 \mathrm{mM}$ of isopropyl- $\beta$-D-thiogalactopyranoside (IPTG) when its $\mathrm{OD}_{600}$ reached 0.8 . The cultures were then incubated at $16^{\circ} \mathrm{C}$ for $20 \mathrm{~h}$.

The cells were harvested by centrifugation at $6000 \mathrm{rpm}$ for $6 \mathrm{~min}$ at $4{ }^{\circ} \mathrm{C}$ and later suspended in buffer A ( $20 \mathrm{mM}$ Tris- $\mathrm{HCl}, \mathrm{pH} 8.5,500 \mathrm{mM} \mathrm{NaCl}, 1 \mathrm{mM}$ PMSF). Sonication of the suspension for $60 \mathrm{~min}$ was followed by centrifugation at $16,000 \mathrm{rpm}$ for $50 \mathrm{~min}$ at $4{ }^{\circ} \mathrm{C}$, which yielded a clear supernatant. His-tagged CLas GMPS was subsequently purified on a Ni-NTA agarose column by using an imidazole gradient. The CLas GMPS was eluted using $500 \mathrm{mM}$ of imidazole and was further purified in a Superdex 200 column (GE Healthcare) equilibrated with buffer B (20 mM Tris- $\mathrm{HCl}, \mathrm{pH} 8.5,150 \mathrm{mM} \mathrm{NaCl}, 10 \%(v / v)$ glycerol) using an AKTAprime Plus System (GE Healthcare). Each eluted fraction was subjected to SDS-PAGE. Highly purified CLas GMPS fractions were pooled and concentrated by ultrafiltration in an Amicon-Ultra-15 Centrifugal Filter Device (Millipore, CA, USA) to $10 \mathrm{mg} / \mathrm{mL}$. The protein concentration was quantified using the Bradford method and bovine serum albumin as a standard.

\subsection{Enzyme Assays and Kinetics}

CLas GMP synthase activity was continuously monitored by measuring the decrease in absorbance at $290 \mathrm{~nm}$ upon conversion of XMP to GMP. A VICTOR Nivo microplate reader (Perkin Elmer, MA, USA) was used to monitor the reaction rates as decrease in absorbance at $290 \mathrm{~nm}$ and $\Delta \varepsilon 290$ was used to calculate the amount of product formed. The assay was performed in $200 \mu \mathrm{L}$ final volume in a 96F well plate with a reaction buffer composed of $50 \mathrm{mM}$ Tris- $\mathrm{HCl}, \mathrm{pH} 8.5,150 \mathrm{mM} \mathrm{XMP,} 2 \mathrm{mM}$ ATP, $5 \mathrm{mM}$ glutamine, $20 \mathrm{mM}$ $\mathrm{MgCl}_{2}, 0.1 \mathrm{mM}$ EDTA, and $0.1 \mathrm{mM}$ DTT. The reaction was initiated by adding $10 \mu \mathrm{g}$ enzyme. The steady-state kinetic parameters were obtained by measuring initial velocities over a range of substrate concentrations. When the concentration of one substrate was varied, the concentrations of the other two substrates were kept at the saturating level. ATP varied over the concentration range $30 \mu \mathrm{M}$ to $4 \mathrm{mM}$, XMP from 5 to $250 \mathrm{mM}$, Gln from 0.25 to $20 \mathrm{mM}$, and $\mathrm{NH}_{4} \mathrm{Cl}$ from 1 to $250 \mathrm{mM}$. The saturating concentrations of ATP, XMP, 
Gln, and $\mathrm{NH}_{4} \mathrm{Cl}$ were 2, 150, 5, and $100 \mathrm{mM}$, respectively. Each initial value represents the average of duplicate measurements, and all data were fitted to the Michaelis-Menten equation using GraphPad Prism (GraphPad Software 8.0, San Diego, CA, USA).

\subsection{Inhibition Assay against CLas GMPS}

The purchased molecules were in vitro screened. The assay was performed in a $200 \mu \mathrm{L}$ final volume in a 96-well plate with a reaction buffer consisting of $50 \mathrm{mM}$ Tris- $\mathrm{HCl}(\mathrm{pH} 8.5)$, $20 \mathrm{mM} \mathrm{MgCl}_{2}, 0.1 \mathrm{mM}$ EDTA, and $0.1 \mathrm{mM}$ DTT. Assays were performed at $30^{\circ} \mathrm{C}$ using $10 \mu \mathrm{g}$ CLas GMPS in the presence or absence of test compounds, and allowed to proceed for $60 \mathrm{~min}$.

The value of $\mathrm{K}_{\mathrm{i}}$ was determined at a fixed saturating concentration of ATP $(1 \mathrm{mM})$ and glutamine $(2 \mathrm{mM})$, different concentrations of XMP $(0.04,0.08,0.15,0.30,0.40$, and $0.50 \mathrm{mM}$ ), and in the presence of increasing concentrations of inhibitor. The concentration of folic acid was 25, 50, and $100 \mu \mathrm{M}$. The concentration of AZD1152 was 1, 5, and $10 \mu \mathrm{M}$. The concentration of DON was 1, 2, 4, and $8 \mu \mathrm{M}$. The concentration of ACI was between 5 and $20 \mu \mathrm{M}$. Each determination of $\mathrm{K}_{\mathrm{i}}$ was derived from duplicate measurements and all data were analyzed using GraphPad Prism (GraphPad Software 8.0).

\section{Results}

\subsection{Model Building and Structure Validation}

Since the experimental 3D structure of the CLas GMPS does not exist, there was a need to predict its structure with a reasonable accuracy. Swiss-Model was employed to generate the three-dimensional structure of CLas GMPS using Neisseria gonorrhoeae GMPS (PDB ID: 5TW7) as a suitable template. The homology model of the CLas GMPS structure was a dimer (Figure 1).

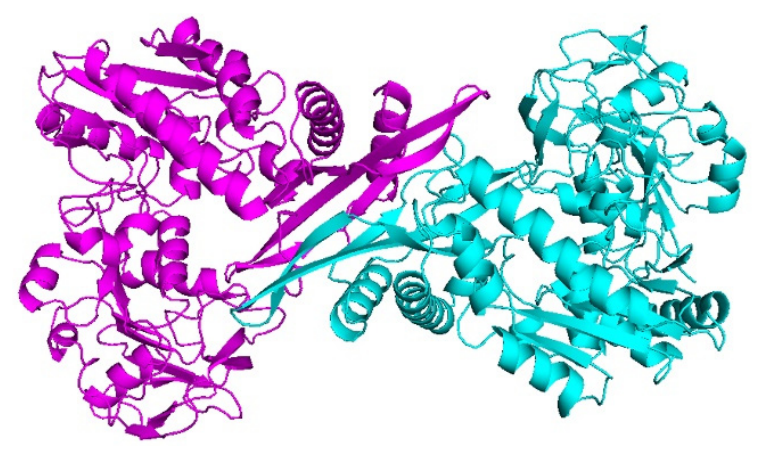

Figure 1. Molecular structure of CLas GMPS.

The quality of the three-dimensional structure of CLas GMPS was assessed using the online platforms (Verify 3D, Procheck). The Verify 3D results showed that $94.85 \%$ of the amino acid residues had an average 3D-1D score $>0.2$ (Figure S1). The Ramachandran plot was analysed by Procheck; the core region had $90.1 \%$ of the residues, $8.8 \%$ of the residues were in the allowed region, the generously allowed region had $0.7 \%$ of the residues, and $0.4 \%$ of the residues were in the disallowed region (Figure S2). These results revealed that this modeled protein had a good quality.

\subsection{Virtual Screening}

We screened 5500 molecules from the ApexBio compound database. The workflow was initiated by compound collection preparation and then subjected to LibDock. LibDock was a module of Discovery Studio 2018 and performed a high-throughput docking by aligning ligand conformations to polar and apolar receptor interaction sites. After screening, 119 compounds (LibDock score $>140$ and molecular weight $<1000 \mathrm{~g} / \mathrm{mol}$ ) within the top $2 \%$ were kept after LibDock. The list of selected structures included 33 compounds from the FDA-approved-drug-library, 15 compounds from the Natural-product-library, 
and 71 compounds from the Inhibitor-library. All selected compounds are listed in Supplementary Table S1. Table 1 shows the top 20 ranked compounds.

Table 1. Top 20 ranked compounds with higher LibDock.

\begin{tabular}{ccccc}
\hline Number & Name & CAS Number & Molecular Weight & LibDock Score \\
\hline 1 & Compound1334 & $722543-31-9$ & 587.54 & 191.661 \\
2 & Compound3170 & $1004316-88-4$ & 776.02 & 183.169 \\
3 & Compound8511 & $81624-55-7$ & 636.79 & 182.643 \\
4 & Compound3997 & $155213-67-5$ & 720.9 & 176.273 \\
5 & Compound5520 & $84366-81-4$ & 829.51 & 174.471 \\
6 & Compound1226 & $612847-09-3$ & 551.64 & 171.437 \\
7 & Compound3975 & $852808-04-9$ & 167.324 \\
8 & Compound2704 & $722544-51-6$ & 813.43 & 166.047 \\
9 & Compound8477 & $1235034-55-5$ & 507.56 & 165.201 \\
10 & Compound7726 & $1439399-58-2$ & 669.79 & 165.127 \\
11 & Compound2503 & $755038-02-9$ & 571.57 & 164.791 \\
12 & Compound3752 & $943319-70-8$ & 521.67 & 163.076 \\
13 & Compound4073 & $641571-10-0$ & 532.56 & 163.076 \\
14 & Compound1591 & $923288-90-8$ & 529.53 & 162.396 \\
15 & Compound6234 & $1062159-35-6$ & 583.99 & 162.366 \\
16 & Compound5313 & $887650-05-7$ & 494.59 & 162.348 \\
17 & Compound4979 & $1633044-56-0$ & 576.62 & 162.072 \\
18 & Compound8081 & $1108743-60-7$ & 634.73 & 161.335 \\
19 & Compound5162 & $7085-55-4$ & 560.64 & 160.757 \\
20 & Compound1446 & $356057-34-6$ & 742.68 & 666.77 \\
\hline
\end{tabular}

\subsection{Molecular Docking}

A total of 119 structures were re-docked against CLas GMPS to select compounds with a relatively low binding affinity to CLas GMPS. Based on the binding affinity estimated by the CDOCKER docking method (-CDOCKER interaction energy $>38.62 \mathrm{kcal} / \mathrm{mol}$ ) in Discovery Studio 2018 (DS 2018, BIOVIA, MA, USA), the top 21 compounds were selected. CDOCKER is a grid-based molecular docking method that uses CHARMm. The receptor is held rigid, however, the ligands are allowed to flex during the process. The results were analysed to identify the ligand binding mechanisms of these molecules, and the binding affinities between receptors and ligands were calculated. Finally, we manually selected 21 hit compounds according to their binding affinity. As illustrated in Table 2, the CDOCKER potential energy of 21 moleculars were lower than the reference ligand DON $(-38.6205 \mathrm{kcal} / \mathrm{mol})$, thereby suggesting that the binding affinity of these 21 compounds with CLas GMPS is higher than DON.

\subsection{ADME and Toxicity Prediction}

The ADME function of Discovery Studio 2018 was used to predict the pharmacologic properties of these 21 selected compounds, including aqueous solubility level, bloodbrain barrier level, hepatotoxicity, human intestinal absorption level, and plasma protein binding properties (Table 3). The solubility of each compound in water at $25{ }^{\circ} \mathrm{C}$ was predicted and it was indicated that compound529, compound1334, compound4419, and compound5481 were soluble in water. Among these four compounds, compound1334, compound4419, and compound5481 are toxic, whereas compound529 is nontoxic. These four compounds perform poorly in human intestinal absorption. Plasma protein binding properties indicated that compound529, compound1334 (AZD1152), compound4419, and compound5481 (folic acid) had weak absorption. Finally, according to low CDOCKER potential energy and good solubility, these four hit molecules were selected and purchased from the ApexBio technology with a purity of $>95 \%$. 
Table 2. CDOCKER potential energy of compounds with CLas GMPS.

\begin{tabular}{ccc}
\hline Number & Name & Cdocker Energy (kcal/mol) \\
\hline 1 & Compound2265 & -90.9198 \\
2 & Compound531 & -89.2316 \\
3 & Compound529 & -83.4206 \\
4 & Compound532 & -81.3088 \\
5 & Compound1334 & -76.7696 \\
6 & Compound5292 & -76.5687 \\
7 & Compound4759 & -75.9609 \\
8 & Compound2293 & -70.4343 \\
9 & Compound4419 & -67.4157 \\
10 & Compound8826 & -66.4995 \\
11 & Compound1926 & -65.2249 \\
12 & Compound5481 & -53.8011 \\
13 & Compound2295 & -51.375 \\
14 & Compound5520 & -50.2805 \\
15 & Compound2476 & -49.5968 \\
16 & Compound8511 & -44.8984 \\
17 & Compound2240 & -42.2788 \\
18 & Compound7726 & -42.1659 \\
19 & Compound2101 & -41.3667 \\
20 & Compound4965 & -40.6106 \\
21 & Compound8477 & -38.8839 \\
22 & DON & -38.6205 \\
\hline
\end{tabular}

Table 3. Pharmacologic properties of compounds.

\begin{tabular}{|c|c|c|c|c|c|c|}
\hline Number & Name & $\begin{array}{l}\text { Solubility } \\
\text { Level }\end{array}$ & BBB Level & Hepatotoxicity & $\begin{array}{l}\text { Absorption } \\
\text { Level }\end{array}$ & PPB Level \\
\hline 1 & Compound2265 & 3 & 4 & 0 & 3 & 0 \\
\hline 2 & Compound531 & 3 & 4 & 0 & 3 & 0 \\
\hline 3 & Compound529 & 4 & 4 & 0 & 3 & 0 \\
\hline 4 & Compound532 & 3 & 4 & 0 & 3 & 0 \\
\hline 5 & Compound1334 & 4 & 4 & 1 & 3 & 0 \\
\hline 6 & Compound5292 & 3 & 4 & 0 & 3 & 0 \\
\hline 7 & Compound4759 & 2 & 4 & 0 & 3 & 0 \\
\hline 8 & Compound2293 & 2 & 4 & 1 & 2 & 0 \\
\hline 9 & Compound4419 & 5 & 4 & 1 & 3 & 0 \\
\hline 10 & Compound8826 & 1 & 4 & 0 & 3 & 1 \\
\hline 11 & Compound1926 & 3 & 4 & 1 & 2 & 0 \\
\hline 12 & Compound5481 & 5 & 4 & 1 & 3 & 0 \\
\hline 13 & Compound2295 & 3 & 4 & 1 & 2 & 1 \\
\hline 14 & Compound5520 & 2 & 4 & 1 & 3 & 0 \\
\hline 15 & Compound 2476 & 3 & 4 & 0 & 3 & 1 \\
\hline 16 & Compound8511 & 1 & 4 & 1 & 2 & 1 \\
\hline 17 & Compound 2240 & 3 & 2 & 1 & 0 & 0 \\
\hline 18 & Compound7726 & 2 & 4 & 1 & 2 & 1 \\
\hline 19 & Compound2101 & 2 & 4 & 1 & 3 & 0 \\
\hline 20 & Compound8477 & 2 & 4 & 1 & 2 & 1 \\
\hline 21 & Compound4965 & 2 & 4 & 0 & 3 & 0 \\
\hline
\end{tabular}

BBB, blood-brain barrier; PPB, plasma protein binding. Aqueous-solubility level: 0, extremely low; 1, very low, but possible; 2, low; 3, good; 4, optimal; 5, too soluble. BBB level: 0, very high penetrant; 1, high; 2, medium; 3, low; 4, undefined. Hepatotoxicity: 0 , nontoxic; 1 , toxic. Human-intestinal absorption level: 0, good; 1, moderate; 2, poor; 3, very poor. PPB: 0, absorbent weak; 1, absorbent strong.

\subsection{Purification of CLas GMPS Protein}

In this study, the GMPS gene from Candidatus Liberibacter asiaticus strain psy62 was cloned, and the plasmid pET28atplus-CLas GMPS was transformed into E. coli BL21 (DE3) for protein expression. CLas GMPS is composed of 520 amino acids and has a predicted molecular weight of $58.7 \mathrm{kDa}$. After $20 \mathrm{~h}$ induction in E. coli at $289 \mathrm{~K}$, full-length His-tagged 
CLas GMPS was expressed heterologously in soluble form. CLas GMPS could be purified using an Ni-NTA resin affinity chromatograph following high-resolution gel filtration column (Superdex 200).

The chromatogram obtained from size exclusion chromatography (SEC) shows two peaks with the elution volumes of 47 and $70 \mathrm{~mL}$ in the $120 \mathrm{~mL}$-Superdex 200 column (Figure 2a). According to the linear regression equation of standard protein, the size of CLas GMPS corresponds to a molecular mass of $119.61 \mathrm{kDa}$. This finding indicated that CLas GMPS forms a homodimer in solution. According to SDS-PAGE analysis, the obtained CLas protein was of high purity (Figure $2 b$ ).

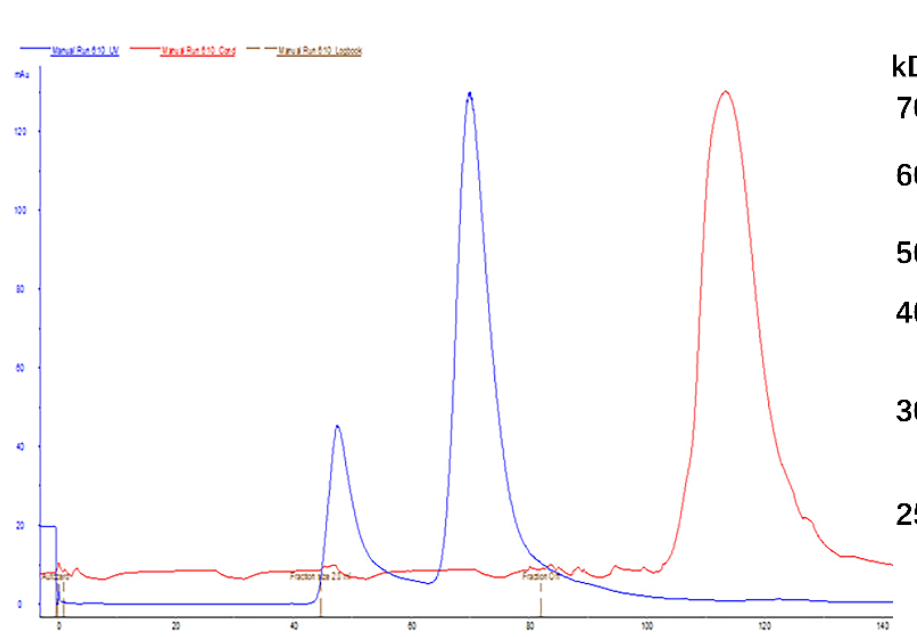

(a)

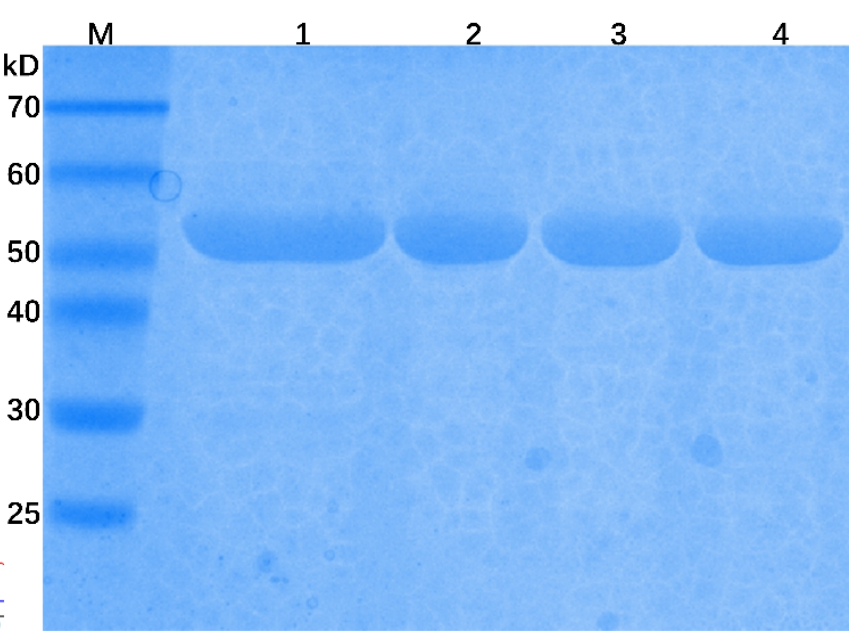

(b)

Figure 2. Protein purification of CLas GMPS. (a) Analysis of CLas GMPS with SEC; (b) SDS-PAGE analysis of CLas GMPS after purification; M: Protein marker; 1: Sample of affinity chromatography; 2-4: Sample of SEC.

\subsection{Kinetic Characterization of CLas GMPS}

For converting XMP to GMP, GMPS utilizes glutamine or ammonia as a nitrogen source. Saturation curves for CLas GMPS-specific activity are plotted against different concentrations of XMP (Figure 3a), ATP (Figure 3b), glutamine (Figure 3c), and $\mathrm{NH}^{4+}$ (Figure 3d). The kinetic properties of CLas GMPS are given in Table 4, according to the standard assay conditions. Fitting the sigmoidal data for the XMP saturation curve yielded values of $61.6 \pm 3.9 \mu \mathrm{M}$ for the Hill constant $\left(\mathrm{K}_{0.5}\right)$. A similar pattern was observed for M. tuberculosis GMPS isozymes, which have $\mathrm{K}_{0.5}$ values of $45 \mu \mathrm{M}$ [35]. The Hill slope (h) of CLas GMPS is 2.29, suggesting positive homotropic cooperative kinetics for XMP. Plots of initial velocity versus ATP concentration at fixed XMP and glutamine concentrations yielded: $K_{M}^{\mathrm{ATP}}=258.2 \pm 24.9 \mu \mathrm{M}$. At saturating XMP and ATP concentration, the velocity of increasing glutamine and $\mathrm{NH} 4+$ concentrations yielded the following values: $K_{M}^{\mathrm{Gln}}=215 \pm 26.76 \mu \mathrm{M}$, and $K_{M}^{\mathrm{NH}^{4+}}=10.9 \pm 1.9 \mathrm{mM}$. The $\mathrm{K}_{\mathrm{M}}$ value for $\mathrm{NH}^{4+}$ is larger than that for glutamine, suggesting that glutamine may be the preferred substrate for CLas GMPS under the physiological conditions. 


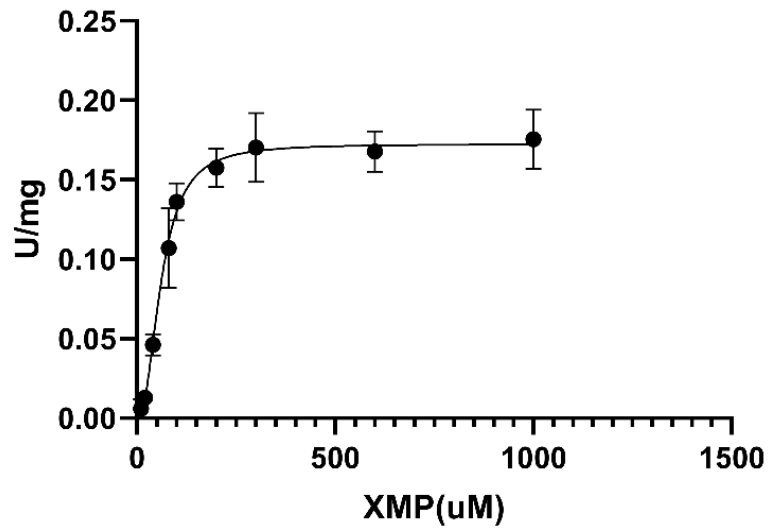

(a)

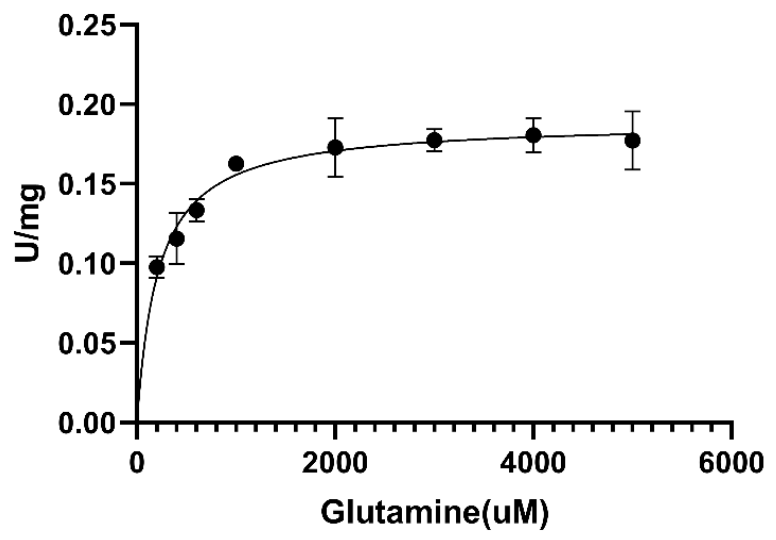

(c)

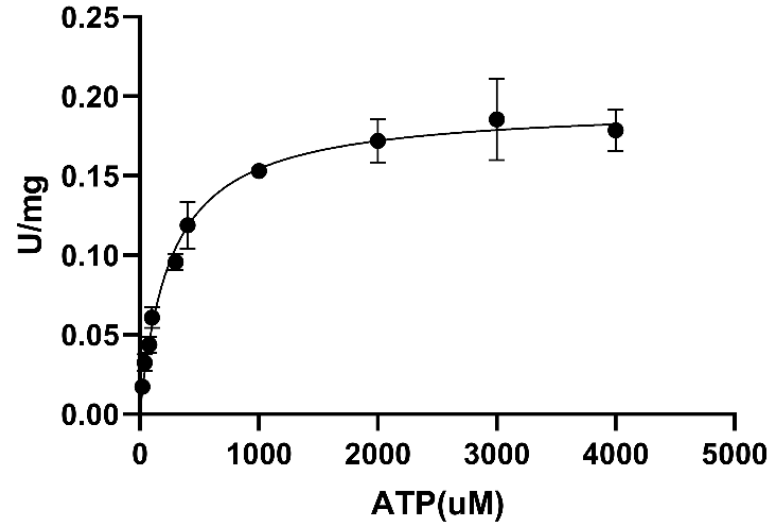

(b)

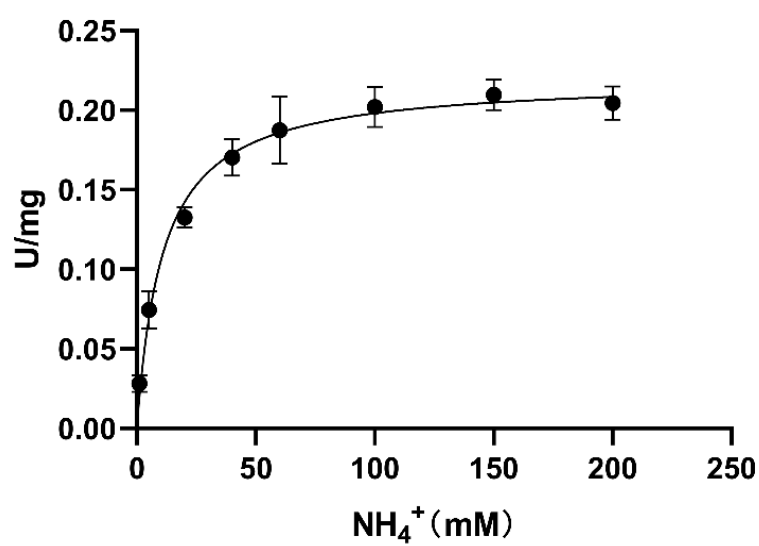

(d)

Figure 3. Apparent kinetic parameters for CLas GMPS. Specific activity as a function of the concentration. (a) XMP; (b) ATP; (c) glutamine; (d) $\mathrm{NH}^{4+}$.

Table 4. Kinetic parameters of different species GMPSs.

\begin{tabular}{|c|c|c|c|c|c|}
\hline Enzyme & $\mathrm{XMP}, \mathrm{K}_{0.5} \mu \mathrm{M}$ & $\mathrm{XMP}, \mathrm{K}_{\mathrm{m}} \mu \mathrm{M}$ & $\mathrm{ATP}, \mathrm{K}_{\mathrm{m}} \mu \mathrm{M}$ & $\begin{array}{c}\text { Glutamine, } K_{m} \\
\mu \mathrm{M}\end{array}$ & $\begin{array}{c}\left(\mathrm{NH}_{4}\right)_{2} \mathrm{SO}_{4}, \mathrm{~K}_{\mathrm{m}} \\
\mathrm{mM}\end{array}$ \\
\hline Ca. L. asiaticus & $61.6 \pm 3.9$ & - & $258.2 \pm 24.89$ & $215 \pm 26.76$ & $10.92 \pm 1.30$ \\
\hline M. tuberculosis a & $45 \pm 1$ & - & $27 \pm 2$ & $1.24( \pm 0.06) \times 10^{3}$ & $13 \pm 1$ \\
\hline P. falciparum $\mathrm{b}$ & - & $16.8 \pm 2$ & $260 \pm 38$ & $472 \pm 69$ & $5.4 \pm 0.8$ \\
\hline E. coli $^{\mathrm{c}}$ & - & 29 & 530 & 1000 & 1.0 \\
\hline
\end{tabular}

${ }^{a}$ Data are from Reference [35]. ${ }^{\mathrm{b}}$ Values are from Reference [30]. ${ }^{\mathrm{c}}$ Data are from Reference [36].

\subsection{Inhibitory Assay against CLas GMPS Anzyme Activity}

To test the inhibition effectiveness of four compounds selected by virtual screening, inhibition assay was performed. First, these four molecules were assessed for their inhibitory activities at a concentration of $1 \mathrm{mM}$ against $C$ Las GMPS. The inhibition mode was determined by incubation time-dependent experiments. DON and ACI were identified as irreversible inhibitors to CLas GMPS; DON showed $52 \%$ inhibition at $1 \mathrm{mM}$ and ACI showed 15\% inhibition at $1 \mathrm{mM}$. Folic acid and AZD1152 showed high inhibition against CLas GMPS. No exponential enzyme decay was observed against CLas GMPS at an extended incubation time (Figure 4). Therefore, folic acid and AZD1152 were attributed to be reversible inhibitors of CLas GMPS. The structure of these compounds (folic acid and AZD1152) is shown in Figure S3. 


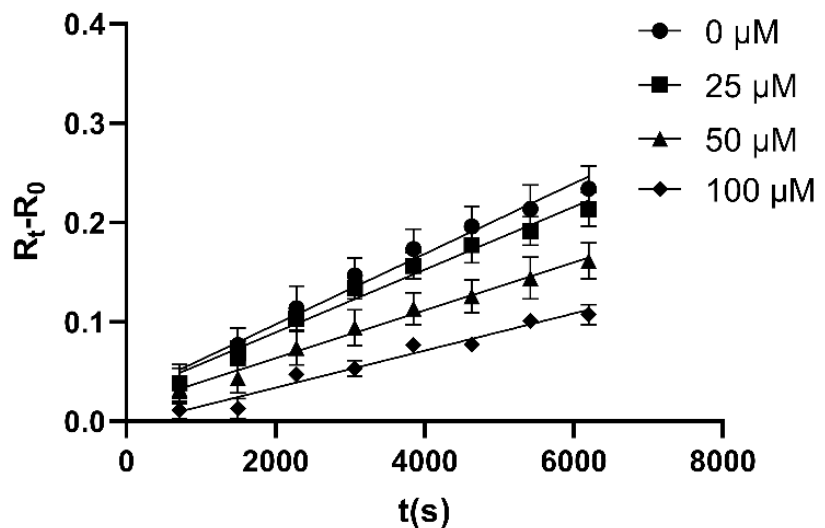

(a)

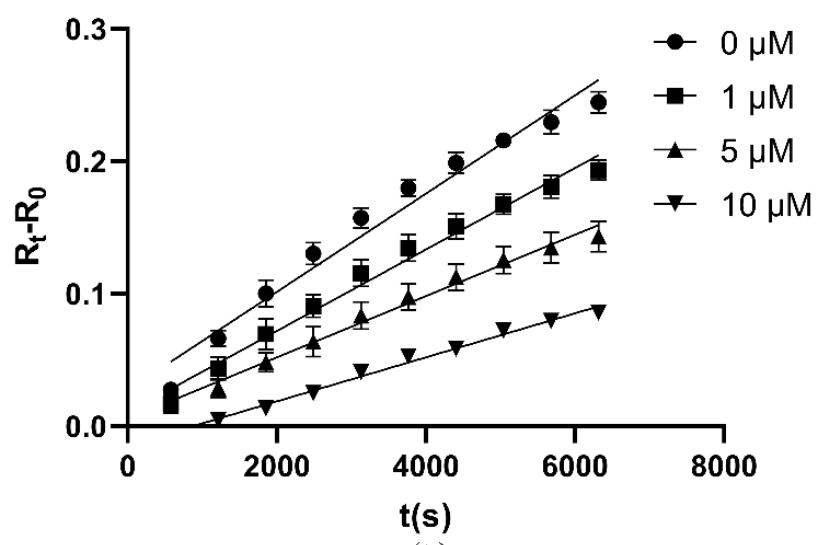

(b)

Figure 4. Folic acid and AZD1152 reversibly inhibit CLas GMPS. Elongating the reaction time, no exponential enzyme decay observed. Substrate concentrations are $1 \mathrm{mM}$ ATP and $2 \mathrm{mM}$ Glutamine for CLas GMPS. (a) Folic acid; (b) AZD1152.

At fixed concentrations of ATP and glutamine, the inhibition constants $\left(\mathrm{K}_{\mathrm{i}}\right)$ were calculated to explore the mechanism of enzyme inhibition. Folic acid is a water-soluble vitamin. Recent demonstration of the strong and stable binding affinity of folic acid to the SARS-COV-2 suggests that it could be used as a potential drug for the treatment of the COVID-19 virus [37]. The $\mathrm{K}_{\mathrm{i}}$ value of folic acid against CLas GMPS was $51.98 \mu \mathrm{M}$ (Figure 5a). AZD1152 is a highly selective Aurora kinase inhibitor [38], The $\mathrm{K}_{\mathrm{i}}$ value of AZD1152 against CLas GMPS is $4.05 \mu \mathrm{M}$ (Figure $5 b$ ).

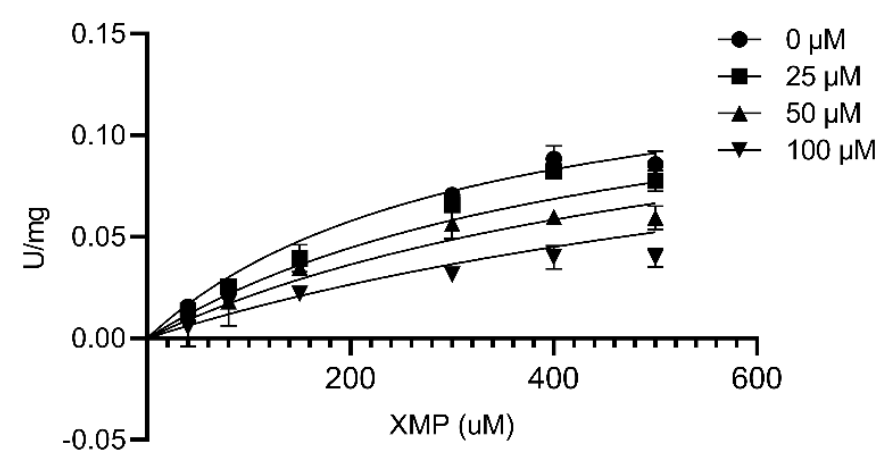

(a)

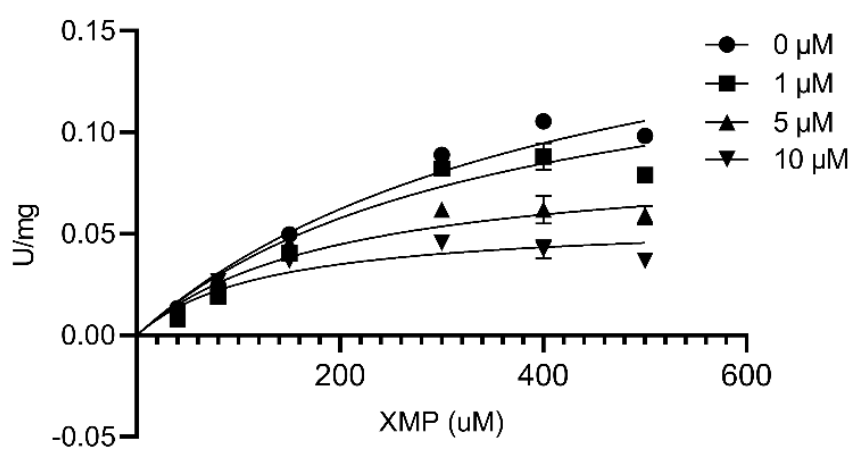

(b)

Figure 5. Inhibition kinetics at different concentrations of compounds by varying the XMP concentrations at a fixed ATP and glutamine concentration. (a) Folic acid; (b) AZD1152.

\subsection{Analysis of Ligand Binding}

The CDOCKER molecular docking module in Discovery Studio 2018 was used to identify the binding mechanism of folic acid and AZD1152. The interactions between CLas GMPS with folic acid and AZD1152 are illustrated in Figure 6. Schematic drawing of interactions between ligands and CLas GMPS is shown in Figure S4. Folic acid formed nine pairs of hydrogen bonds with VAL233, ASP234, GLN329, THR331, and ASP335 of CLas GMPS, and four electrostatic interactions with ASP335, GLU369, LYS376, and ARG380 of CLas GMPS were formed in this complex (Figure 6a,b). Four hydrogen bonds formed between AZD1152 and the residues GLY330, LEU332, GLN329, and GLY357 of CLas GMPS. There are three electrostatic interactions observed in the CLas GMPS-folic acid complex, including the $\pi$-Orbitals between folic acid and ASP234 and ASP335 of CLas GMPS. Moreover, one salt bridge is formed with ASP335 of CLas GMPS, and one halogen bond is observed with SER347 of CLas GMPS (Figure 6c,d). 


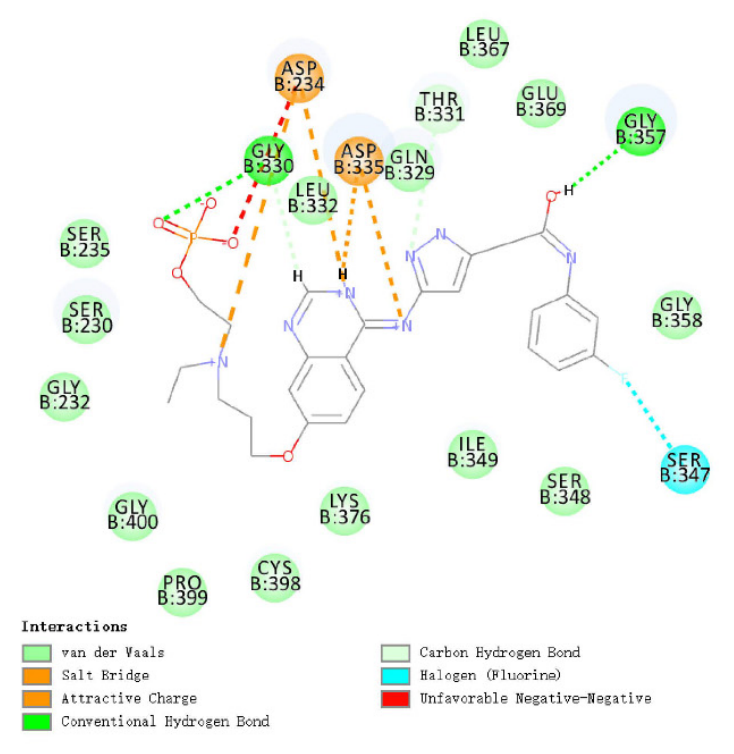

(a)

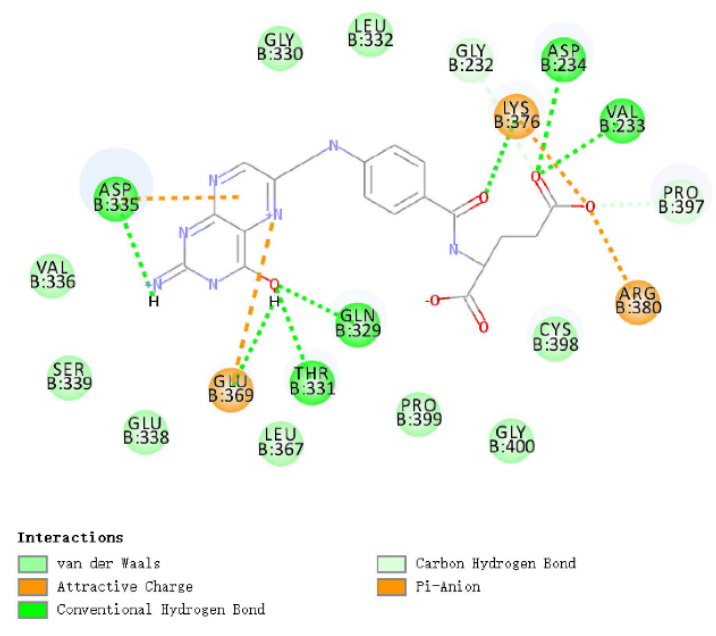

(c)

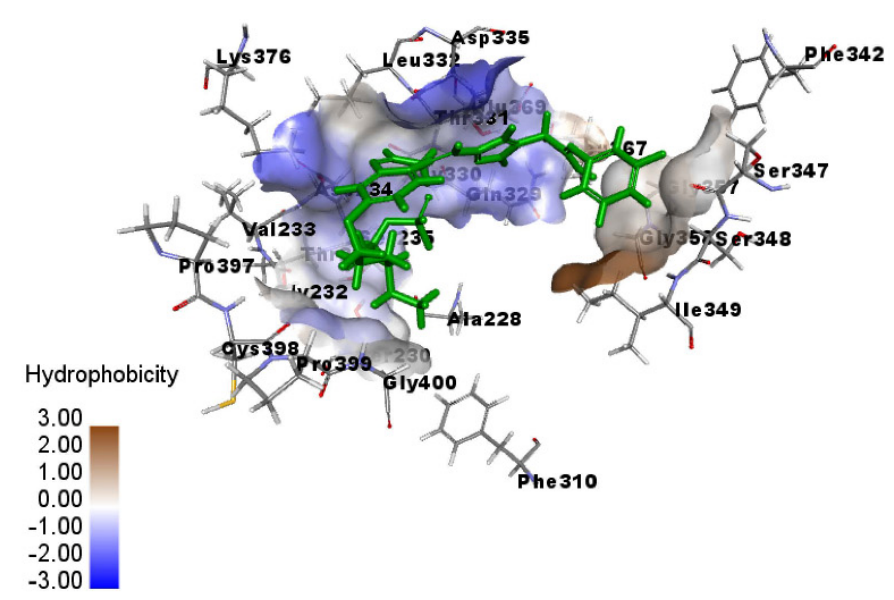

(b)

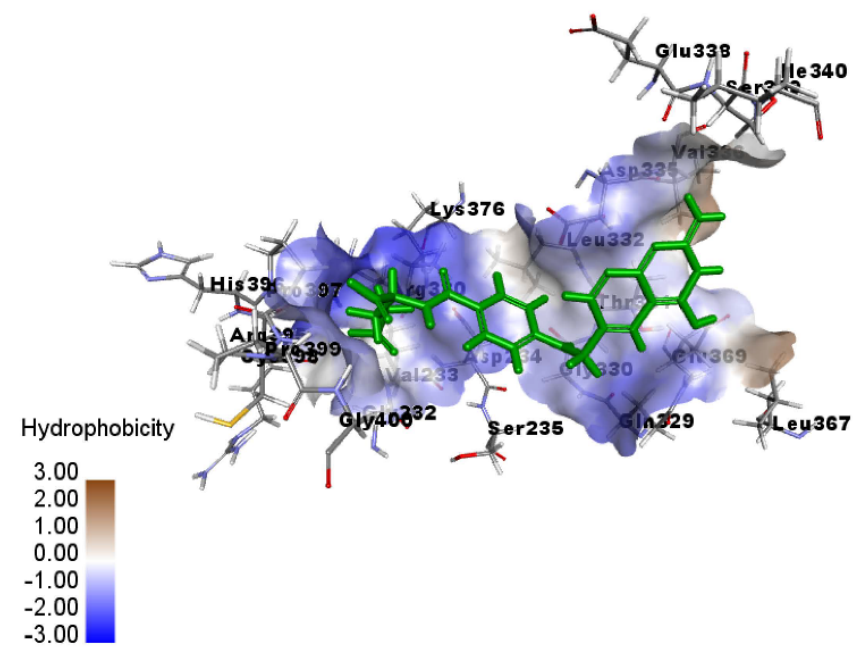

(d)

Figure 6. Schematic of intermolecular interaction of the predicted binding modes of CLas GMPS with the molecules. (a) 2D details of CLas GMPS and folic acid interaction; (b) 3D details of CLas GMPS and folic acid (blue) interaction; (c) 2D details of CLas GMPS and AZD1152 (blue) interaction; (d) 3D details of CLas GMPS and AZD1152 interaction.

\section{Discussion}

Citrus huanglongbing (HLB) is a destructive disease that has caused substantial crop losses. Various methods have been applied to control the spread of HLB [7,8]. However, the effectiveness of these approaches is often inconsistent under field conditions [20]. Consequently, new strategies and methods are urgently needed to prevent and control citrus HLB. Structure-based drug screening is a fast and effective method for screening specific inhibitors. GMPS is a key enzyme in the purine biosynthetic pathway. The inhibition of GMPS activity can reduce the ability of pathogen infection [24]. There is an increasing recognition that GMPS can be used as the potential antibacterial target [39]. Here, we used homology modeling to determine the structure of CLas GMPS and used structure-based virtual screening to identify the novel potent antimicrobial compound(s). Further inhibitory assays were performed to explore the inhibitory potential of the selected compounds.

In this study, 5500 molecules were taken from the ApexBio technology for virtual screening, followed by CDOCKER and inhibitory assay. After the screening by LibDock, 
123 compounds had higher LibDock scores (LibDock score $>140$ and molecular weight $<1000 \mathrm{~g} / \mathrm{mol}$ ), indicating that these 123 compounds could form a more stable complex with CLas GMPS. Therefore, these 123 compounds and two known GMPS inhibitors (ACI and DON) were selected for CDOCK analysis. The binding affinities of 21 compounds with CLas GMPS were found to be higher than that those exhibited by DON. ADME prediction was performed to predict the pharmacologic properties of these compounds, and the result indicated that four compounds (AZD1152, folic acid, Z-DEVD-FMK, and mitoxantrone-Hcl) may have better solubility.

Although bacterial enzymes have high sequence similarities, inhibition by the same inhibitor chemotype may reveal significant differences between different bacterial target enzymes [40,41]. With two known hGMPS inhibitors, Psicofuranine and decoyinine, the $\mathrm{IC}_{50}$ values were found to be of 17.3 and $46.5 \mu \mathrm{M}$, respectively [30]. Although $P f$ GMPS and hGMPS have $20-30 \%$ sequence similarity, psicofuranine at $0.5 \mathrm{mM}$ showed $25 \%$ inhibition of Pf GMPS activity and decoynine displayed no effect on purified $P f$ GMPS [29]. Therefore, it is vital to establish a high-throughput screening method for finding novel agents that work against CLas GMPS. A previous study demonstrated that a single residue difference is responsible for mycophenolic acid resistance, despite a high similarity in the binding sites of the two enzymes. [42]. Accordingly, the search for inhibitory compounds toward a given target enzyme performed by virtual screening only is insufficient, and results of this search require further in vivo and in vitro experimental validation. Employing a new database that includes known compounds for screening against a novel target is very advantageous. This approach considerably reduces financial and temporal burdens in the drug discovery process. In this study, folic acid and AZD1152 were identified as inhibitors of CLas GMPS in the screening process. Therefore, this study is the first report that identifies folic acid and AZD1152 as CLas GMPS inhibitors. The $\mathrm{K}_{\mathrm{m}}$ values for XMP, ATP, glutamine, and ammonium ions are shown in Table 1. CLas GMPS has the lowest affinity to XMP and the highest affinity towards glutamine. CLas GMPS was homodimer in solution. This result is consistent with the oligomeric state of GMPS proteins from E. coli [43], P. falciparum [30], and P. horikoshii [44]. However, GMPS proteins from humans are monomeric [34] due to a large insertion that seems to influence dimer formation [45]. The structural and mechanistic differences between GMPS enzymes from different species emphasizes the utility of the structure-based compound method for screening the potential GMPS inhibitors. Standard enzyme activity assay showed that the $\mathrm{K}_{\mathrm{i}}$ values of folic acid and AZD1152 were 51.98 and $4.05 \mu \mathrm{M}$, respectively. Folic acid and AZD1152 showed greater potency than ACI or DON. DON showed 52\% inhibition and ACI showed $15 \%$ inhibition against CLas GMPS at $1 \mathrm{mM}$. Interestingly, AZD1152 is a pro-drug of barasertib-HQPA. The CDOCKER module analysis demonstrates that the CDOCKER interaction energy of AZD1152 $(-76.77 \mathrm{kcal} / \mathrm{mol})$ was obviously lower than that of Barasertib-HQPA $(-23.13 \mathrm{kcal} / \mathrm{mol})$, which suggests AZD1152 to have a higher binding affinity with CLas GMPS compared with barasertib-HQPA. Identification of these two compounds certainly provides beneficial information for future structure-activity relationship studies of CLas GMPS inhibitors. This study provides a solid basis for using folic acid and AZD1152 as parent compounds in the future search of potent agents for controling citrus HLB.

\section{Conclusions}

This study performed a virtual screening to discover the appropriate parent compounds that inhibit CLas GMPS. According to the inhibitory assay against CLas GMPS activity, two compounds (folic acid and AZD1152) were confirmed as CLas GMPS inhibitors. Moreover, this study identified some drug candidates that may contribute to the design and improvement of CLas GMPS inhibitors. 
Supplementary Materials: The following are available online at https: / www.mdpi.com/article/ 10.3390/biology10070594/s1, Figure S1: Verify 3D results of the refined CLas GMPS, Figure S2: Ramachandran plot of CLas GMPS by PROCHECK, Figure S3: Structures of compounds selected from virtual screening and Enzyme Kinetic, Figure S4: Schematic drawing of interactions between ligands and CLas GMPS, Table S1: Compounds with higher LibDock.

Author Contributions: Data curation, J.N. and P.Z.; Formal analysis, J.N.; Funding acquisition, L.J.; Project administration, S.Z.; Writing-review \& editing, J.N., S.Z. and L.J. All authors have read and agreed to the published version of the manuscript.

Funding: This research was funded by National Natural Science Foundation of China (No. 31872064), and National key research and development plan (2019YFD1001802 and 2018YFD0201505).

Institutional Review Board Statement: Not applicable.

Informed Consent Statement: Not applicable.

Data Availability Statement: All data is contained within the article. The datasets analyzed during the current study are available from the corresponding author on reasonable request.

Acknowledgments: The authors would like to thank the State Key Laboratory of Agricultural Microbiology Core Facility for assistance in the experiment.

Conflicts of Interest: The authors declare no conflict of interest.

\section{References}

1. Wang, N.; Trivedi, P. Citrus huanglongbing: A newly relevant disease presents unprecedented challenges. Phytopathology 2013, 103, 652-665. [CrossRef]

2. da Graca, J.V.; Douhan, G.W.; Halbert, S.E.; Keremane, M.L.; Lee, R.F.; Vidalakis, G.; Zhao, H. Huanglongbing: An overview of a complex pathosystem ravaging the world's citrus. J. Integr. Plant Biol. 2016, 58, 373-387. [CrossRef]

3. Wang, N.; Pierson, E.A.; Setubal, J.C.; Xu, J.; Levy, J.G.; Zhang, Y.; Li, J.; Rangel, L.T.; Martins, J., Jr. The Candidatus Liberibacterhost interface: Insights into pathogenesis mechanisms and disease control. Annu. Rev. Phytopathol. 2017, 55, 451-482. [CrossRef]

4. Bove, J.M. Huanglongbing: A destructive, newly-emerging, century-old disease of citrus. J. Plant Pathol. 2006, 88, 7-37.

5. Gottwald, T.R.; Graça, J.V.; Bassanezi, R.B. Citrus huanglongbing: The pathogen and its impact. Plant Health Prog. 2007 , 8, 31. [CrossRef]

6. Wang, N. The citrus huanglongbing crisis and potential solutions. Mol. Plant 2019, 12, 607-609. [CrossRef]

7. Lin, K.H. Observations on yellow shoot on citrus. Etiological studies of yellow shoot of citrus. Acta Phytopathol. Sin. 1956, 2, 13-42.

8. Bassanezi, R.B.; Montesino, L.H.; Gimenes-Fernandes, N.; Yamamoto, P.T.; Gottwald, T.R.; Amorim, L.; Bergamin Filho, A. Efficacy of area-wide inoculum reduction and vector control on temporal progress of huanglongbing in young sweet orange plantings. Plant Dis. 2013, 97, 789-796. [CrossRef] [PubMed]

9. Zhang, M.; Powell, C.A.; Zhou, L.; He, Z.; Stover, E.; Duan, Y. Chemical compounds effective against the citrus huanglongbing bacterium 'Candidatus Liberibacter asiaticus' in planta. Phytopathology 2011, 101, 1097-1103. [CrossRef] [PubMed]

10. Al-Rimawi, F.; Hijaz, F.; Nehela, Y.; Batuman, O.; Killiny, N. Uptake, translocation, and stability of oxytetracycline and streptomycin in citrus plants. Antibiotics 2019, 8, 196. [CrossRef] [PubMed]

11. Killiny, N.; Hijaz, F.; Al-Rimawi, F.; Batuman, O. Translocation of oxytetracycline in citrus plants after root drench and stem delivery. Proc. Fla. State Hort. Soc. 2019, 132, 68-71.

12. Shin, K.; Ascunce, M.S.; Narouei-Khandan, H.A.; Sun, X.; Jones, D.; Kolawole, O.O.; Goss, E.M.; van Bruggen, A.H.C. Effects and side effects of penicillin injection in huanglongbing affected grapefruit trees. Crop Protect. 2016, 90, 106-116. [CrossRef]

13. Zhang, M.; Karuppaiya, P.; Zheng, D.; Sun, X.; Bai, J.; Ferrarezi, R.S.; Powell, C.A.; Duan, Y. Field evaluation of chemotherapy on HLB-affected citrus trees with emphasis on fruit yield and quality. Front. Plant Sci. 2021, 12, 611287. [CrossRef]

14. Barnett, M.J.; Solow-Cordero, D.E.; Long, S.R. A high-throughput system to identify inhibitors of Candidatus Liberibacter asiaticus transcription regulators. Proc. Natl. Acad. Sci. USA 2019, 116, 18009-18014. [CrossRef] [PubMed]

15. Nan, J.; Zhang, S.; Zhan, P.; Jiang, L. Evaluation of bronopol and disulfiram as potential Candidatus Liberibacter asiaticus inosine 5'-monophosphate dehydrogenase inhibitors by using molecular docking and enzyme kinetic. Molecules 2020, $25,2313$. [CrossRef] [PubMed]

16. Huang, C.-Y.; Araujo, K.; Sanchez, J.N.; Kund, G.; Trumble, J.; Roper, C.; Godfrey, K.E.; Jin, H. A stable antimicrobial peptide with dual functions of treating and preventing citrus Huanglongbing. Proc. Natl. Acad. Sci. USA 2021, 118, e2019628118. [CrossRef] [PubMed]

17. Li, J.; Trivedi, P.; Wang, N. Field evaluation of plant defense inducers for the control of citrus Huanglongbing. Phytopathology 2016, 106, 37-46. [CrossRef] 
18. Hu, J.; Jiang, J.; Wang, N. Control of citrus huanglongbing via trunk injection of plant defense activators and antibiotics. Phytopathology 2018, 108, 186-195. [CrossRef]

19. Nan, J.; Zhang, S.; Jiang, L. Antibacterial potential of Bacillus amyloliquefaciens GJ1 against citrus huanglongbing. Plants 2021, 10, 261. [CrossRef]

20. Zhang, M.; Yang, C.; Powell, C.A.; Avery, P.B.; Wang, J.; Huang, Y.; Duan, Y. Field evaluation of integrated management for mitigating citrus huanglongbing in Florida. Front. Plant. Sci. 2019, 9, 1890. [CrossRef]

21. Cheviet, T.; Lefebvre-Tournier, I.; Wein, S.; Peyrottes, S. Plasmodium purine metabolism and its inhibition by nucleoside and nucleotide analogues. J. Med. Chem. 2019, 62, 8365-8391. [CrossRef]

22. McConkey, G.A. Plasmodium falciparum: Isolation and characterisation of a gene encoding protozoan GMP synthase. Exp. Parasitol. 2000, 94, 23-32. [CrossRef]

23. Massiere, F.; Badet-Denisot, M.A. The mechanism of glutamine-dependent amidotransferases. Cell. Mol. Life Sci. 1998, 54, 205-222. [CrossRef]

24. Long, H.; Cameron, S.; Yu, L.; Rao, Y. De novo GMP synthesis is required for axon guidance in Drosophila. Genetics 2006, 172, 1633-1642. [CrossRef]

25. Li, Q.; Leija, C.; Rijo-Ferreira, F.; Chen, J.; Cestari, I.; Stuart, K.; Tu, B.P.; Phillips, M.A. GMP synthase is essential for viability and infectivity of Trypanosoma brucei despite a redundant purine salvage pathway. Mol. Microbiol. 2015, 97, 1006-1020. [CrossRef] [PubMed]

26. Zalkin, H.; Truitt, C.D. Characteriztion of glutamine site of Escherichia-coli guanosine 5'-monophosphate synthetase. J. Biol. Chem. 1977, 252, 5431-5436. [CrossRef]

27. Chittur, S.V.; Klem, T.J.; Shafer, C.M.; Davisson, V.J. Mechanism for acivicin inactivation of triad glutamine amidotransferases. Biochemistry 2001, 40, 876-887. [CrossRef]

28. Rodriguez-Suarez, R.; Xu, D.; Veillette, K.; Davison, J.; Sillaots, S.; Kauffman, S.; Hu, W.; Bowman, J.; Martel, N.; Trosok, S.; et al. Mechanism-of-action determination of GMP synthase inhibitors and target validation in Candida albicans and Aspergillus fumigatus. Chem. Biol. 2007, 14, 1163-1175. [CrossRef]

29. Nakamura, J.; Lou, L. Biochemical-characterization of human GMP synthetase. J. Biol. Chem. 1995, 270, 7347-7353. [CrossRef]

30. Bhat, J.Y.; Shastri, B.G.; Balaram, H. Kinetic and biochemical characterization of Plasmodium falciparum GMP synthetase. Biochem. J. 2008, 409, 263-273. [CrossRef]

31. Eisenberg, D.; Luthy, R.; Bowie, J.U. VERIFY3D: Assessment of protein models with three-dimensional profiles. Methods Enzymol. 1997, 277, 396-404.

32. Laskowski, R.A.; Macarthur, M.W.; Moss, D.S.; Thornton, J.M. Procheck-A Program to Check the Stereochemical Quality of Protein Structures. J. Appl. Crystallogr. 1993, 26, 283-291. [CrossRef]

33. Diller, D.J.; Merz, K.M., Jr. High throughput docking for library design and library prioritization. Proteins Struct. Funct. Genet. 2001, 43, 113-124. [CrossRef]

34. Wu, G.; Robertson, D.H.; Brooks, C.L.; Vieth, M. Detailed analysis of grid-based molecular docking: A case study of CDOCKER-A CHARMm-based MD docking algorithm. J. Comput. Chem. 2003, 24, 1549-1562. [CrossRef]

35. Franco, T.M.A.; Rostirolla, D.C.; Ducati, R.G.; Lorenzini, D.M.; Basso, L.A.; Santos, D.S. Biochemical characterization of recombinant guaA-encoded guanosine monophosphate synthetase (EC 6.3.5.2) from Mycobacterium tuberculosis H37Rv strain. Arch. Biochem. Biophys. 2012, 517, 1-11. [CrossRef]

36. Sakamoto, N.; Hatfield, G.W.; Moyed, H.S. Physical properties and subunit structure of xanthosine $5^{\prime}$-phosphate aminase. J. Biol. Chem. 1972, 247, 5880-5887. [CrossRef]

37. Kumar, V.; Kancharla, S.; Jena, M.K. In silico virtual screening-based study of nutraceuticals predicts the therapeutic potentials of folic acid and its derivatives against COVID-19. VirusDisease 2021, 32, 1-9. [CrossRef]

38. Oser, M.G.; Fonseca, R.; Chakraborty, A.A.; Brough, R.; Spektor, A.; Jennings, R.B.; Flaifel, A.; Novak, J.S.; Gulati, A.; Buss, E.; et al. Cells lacking the RB1 tumor suppressor gene are hyperdependent on aurora B kinase for survival. Cancer Discov. 2019, 9, $230-247$. [CrossRef]

39. Ballut, L.; Violot, S.; Shivakumaraswamy, S.; Thota, L.P.; Sathya, M.; Kunala, J.; Dijkstra, B.W.; Terreux, R.; Haser, R.; Balaram, H.; et al. Active site coupling in Plasmodium falciparum GMP synthetase is triggered by domain rotation. Nat. Commun. 2015, 6, 8930. [CrossRef]

40. Kirubakaran, S.; Gorla, S.K.; Sharling, L.; Zhang, M.; Liu, X.; Ray, S.S.; MacPherson, I.S.; Striepen, B.; Hedstrom, L.; Cuny, G.D. Structure-activity relationship study of selective benzimidazole-based inhibitors of Cryptosporidium parvum IMPDH. Bioorganic Med. Chem. Lett. 2012, 22, 1985-1988. [CrossRef]

41. Makowska-Grzyska, M.; Kim, Y.; Maltseva, N.; Osipiuk, J.; Gu, M.; Zhang, M.; Mandapati, K.; Gollapalli, D.R.; Gorla, S.K.; Hedstrom, L.; et al. A novel cofactor-binding mode in bacterial IMP dehydrogenases explains inhibitor selectivity. J. Biol. Chem. 2015, 290, 5893-5911. [CrossRef] [PubMed]

42. Freedman, R.; Yu, R.; Sarkis, A.W.; Hedstrom, L. A structural determinant of mycophenolic acid resistance in eukaryotic inosine 50-monophosphate dehydrogenases. Protein Sci. Publ. Protein Soc. 2020, 29, 686-694. [CrossRef]

43. Abbott, J.L.; Newell, J.M.; Lightcap, C.M.; Olanich, M.E.; Loughlin, D.T.; Weller, M.A.; Lam, G.; Pollack, S.; Patton, W.A. The effects of removing the GAT domain from E-coli GMP synthetase. Protein J. 2006, 25, 483-491. [CrossRef] [PubMed] 
44. Maruoka, S.; Horita, S.; Lee, W.C.; Nagata, K.; Tanokura, M. Crystal structure of the ATPPase subunit and its substrate-dependent association with the GATase subunit: A novel regulatory mechanism for a two-subunit-type GMP synthetase from Pyrococcus horikoshii OT3. J. Mol. Biol. 2010, 395, 417-429. [CrossRef] [PubMed]

45. Tesmer, J.G.; Klem, T.J.; Deras, M.L.; Davisson, V.J.; Smith, J.L. The crystal structure of GMP synthetase reveals a novel catalytic triad and is a structural paradigm for two enzyme families. Nat. Struct. Biol. 1996, 3, 74-86. [CrossRef] [PubMed] 